\title{
BREAKUP OF AERATED-LIQUID JETS IN SUPERSONIC CROSSFLOWS
}

\author{
K.A. Sallam, C. Aalburg, G.M. Faeth* \\ The University of Michigan, Ann Arbor, MI 48109-2140 \\ K.-C. Lin \\ Taitech Inc., Beavercreek, OH 45430 \\ C.D. Carter, T.A. Jackson \\ Air Force Research Laboratory, Wright-Patterson AFB, OH 45433
}

\begin{abstract}
An experimental investigation of the primary breakup of aerated-liquid jets (in the annular flow regime) in supersonic crossflow is described. Singleand double-pulsed shadowgraphy and holography were used to study properties of the liquid sheet as well as outcomes of breakup in the dense spray region near the liquid jet itself that has been inaccessible to past studies using phase Doppler particle analyzers. The results show that the underexpanded internal gas phase forces the liquid sheet into a conical shape upon ejecting from the nozzle exit. Surface breakup along both the downstream and the upstream sides of the jet as well as increased breakup times of the liquid core as compared with pure-liquid jets in subsonic crossflows suggest weak aerodynamic effects of the crossflow near the jet exit. Surface velocities of the liquid sheet were measured and used to develop correlations for the liquid sheet thickness. Sizes of ligaments and drops were measured along the liquid surface and were found to have constant diameters of $30 \mu \mathrm{m}$ and $40 \mu \mathrm{m}$, respectively, that were independent of the wide ranges of aeration levels,
\end{abstract}

*A.B. Modine Professor, Department of Aerospace Engineering, Fellow AIAA, Corresponding author, Tel.: +1-734-764-7202; Fax: +1-734-936-0106; E.mail: gmfaeth@umich.edu (G.M. Faeth). liquid/gas momentum flux ratios, nozzle diameters and liquid properties considered during the present investigation. Drop size distributions satisfied Simmons' universal root-normal drop-size distribution function with a relatively constant ratio of $\mathrm{MMD} / \mathrm{SMD}=1.07$.

\section{NOMENCLATURE}

$\mathrm{C}_{\mathrm{v}}=$ velocity coefficient

$\mathrm{d}=$ diameter

GLR = aerating gas/liquid mass ratio

$\mathrm{M}=$ freestream Mach number

MMD $=$ mass median diameter

$\mathrm{P} \quad=$ stagnation pressure

$\mathrm{p}=$ static pressure

$\mathrm{q}=$ jet/freestream momentum flux ratio, $\rho_{\mathrm{L}} \mathrm{V}_{\mathrm{L}}^{2} /\left(\rho_{\mathrm{G}} \mathrm{u}_{\infty}^{2}\right)$

$\mathrm{Q}=$ volumetric flow rate

SMD $=$ Sauter mean diameter, $\Sigma \mathrm{d}_{\mathrm{i}}{ }^{3} / \Sigma \mathrm{d}_{\mathrm{i}}{ }^{2}, \mathrm{i}$ for all droplets

$\mathrm{T}=$ temperature

$\mathrm{t}=$ time

$\mathrm{t}^{*}=$ characteristic time, $\mathrm{d}_{\mathrm{L}}\left(\rho_{\mathrm{L}} / \rho_{\mathrm{G}}\right)^{1 / 2} / \mathrm{u}_{\infty}$

$\mathrm{u}=$ jet crosstream velocity

$\mathrm{v}=$ jet streamwise velocity

$\mathrm{x}=$ crosstream distance

$\mathrm{y}=$ streamwise distance

$\mu \quad=$ molecular viscosity

$\rho=$ density

$\sigma=$ surface tension

$\Theta=$ angle between liquid surface and vertical direction 


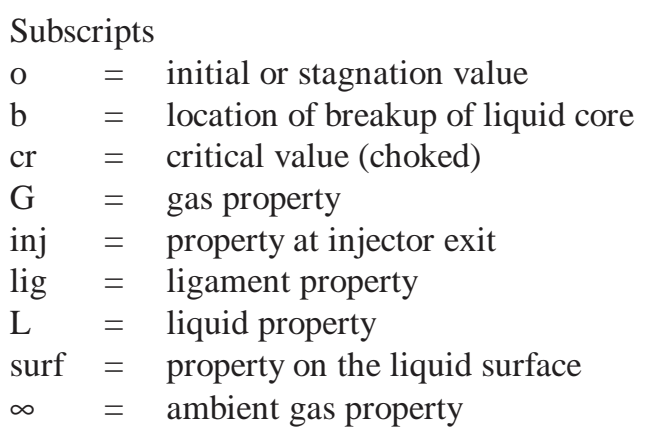

\section{INTRODUCTION}

Liquid atomization has been studied extensively due to numerous applications for transportation, industrial and agricultural processes. The mixing behavior, combustion efficiency and combustion stability of liquid-fueled air-breathing propulsion systems, for example, depends to a large extent on liquid jet atomization performance. Aerated-liquid jet breakup (also known as effervescent or barbotage breakup) has been popularized by Lefebvre et al. ${ }^{1}$ and is of interest due to its demonstrated capabilities to generate finelyatomized sprays. These properties are attained by assuring intimate contact between the liquid phase and a gas phase by injecting gas directly into the liquid flow immediately upstream of the exit orifice. Upon passage of the two-phase mixture through the injector exit orifice, the internal gas phase expands to generally yield an annular flow in the injector orifice, squeezing the liquid into thin sheets and ligaments whose small cross stream dimension assures a finely atomized spray, as illustrated in Fig. 1.

There is a large literature about liquid jets in gaseous crossflows. Studies of pure-liquid jets by Fuller et $\mathrm{al}^{2}$ and $\mathrm{Wu}$ et $\mathrm{al}^{3}$ focused on jet trajectories for various jet exit and crossflow conditions, whereas Mazallon et al. ${ }^{4}$ and Sallam et al. ${ }^{5}$ mainly investigated the primary breakup properties of round nonturbulent and turbulent liquid jets in uniform gaseous crossflows, including the various breakup modes, drop size distributions and velocities and rates of breakup. The recent work by Lin et al. ${ }^{6-10}$ and Mathur et al. ${ }^{11}$ considered both pure-liquid and aerated-liquid jets in gaseous crossflows. Their studies generated information about velocity, liquid volume flux and drop size distributions after breakup, showing that aeratedliquid jets can generate smaller droplets with larger velocities and a more uniform volume flux at lower injection pressures than conventional jets within a relatively short distance after injection. In addition, the spray penetration height and the cross-sectional area of the spray plume for an aerated-liquid jet are larger than those of a pure-liquid jet under the same ambient and liquid flow conditions. These investigations were based on shadowgraph and phase-Doppler particle anemometry measurements. In order to avoid problems of large drop number densities and large liquid volume fractions, however, the measurements had to be performed at some distance from the initial breakup location. The characteristics of the spray breakup in the nearinjector field, and the driving mechanism behind the effervescent induced breakup, however, remain unknown.

The objectives of the present investigation were thus to measure the properties of aerated liquid jet breakup in supersonic crossflow by emphasizing the outcomes of breakup in the dense spray region extending right up to the liquid jet itself. Pulsed shadowgraphy and holography were employed in order to consider spray cone angles, the location of the end of the liquid core and drop size and velocity distributions after breakup, seeking to quantify effects of aeration levels, momentum flux, nozzle diameters and liquid properties on the breakup properties of aerated-liquid jets in supersonic crossflows.

\section{EXPERIMENTAL METHODS}

\section{$\underline{\text { Apparatus }}$}

The experiments were carried out inside a supersonic wind tunnel in Test Cell 19 of Air Force Research Laboratory, Wright-Patterson Air Force Base. This facility is a continuous-run, open-loop, rectangular wind tunnel with a test section having a $12.7 \mathrm{~cm}$ height, a $15.2 \mathrm{~cm}$ width and a $76.2 \mathrm{~cm}$ length. The flow Mach number was constant at $\mathrm{M}=1.94$ yielding crossflow velocities behind a normal shock wave in the range of $u_{\infty}=195-263 \mathrm{~m} / \mathrm{s}$, depending on the stagnation temperature of the air in the wind tunnel. Air pressures and temperatures were measured using strain gauges and k-type thermocouples with uncertainties less than $1 \%$. A schematic of the wind tunnel is illustrated in Fig. 2.

A plain-orifice aerated-liquid injector, consisting of an internal tube for the aerating gas flow and an external tube for the liquid flow was 
flush mounted at the bottom surface of the wind tunnel (see Fig. 3). The aerating gas flowed through the internal tube and passed through several $100-\mu \mathrm{m}$ orifices located at the end of the tube, which is 25 $\mathrm{mm}$ upstream of the entrance to the final discharge orifice. This allows the aerating gas to fully mix with the liquid to form the two-phase annular flow. Two nozzles with a length/diameter ratio of 20 and orifice diameters of 0.5 and $1.0 \mathrm{~mm}$ were used to inject three different liquids, i.e. water, alcohol and glycerol, vertically upward into the crossflow. The aerating gas was nitrogen.

The injection system consisted of a liquid tank with a large internal volume of $0.144 \mathrm{~m}^{3}$ to insure constant liquid supply. Test liquids were filled into the tank and pressurized with high-pressure nitrogen before each experiment. The pressure was varied to provide various liquid velocities at the nozzle orifice. Both the liquid and the aerating gas volumetric flow rates were controlled by pressure regulators and measured by flow meters respectively. Gas/liquid mass ratios (GLR) between 2-10\% were used, ensuring that the internal multiphase flow was in the annular flow regime (see Kim and Lee ${ }^{12}$ ). The flow meters were calibrated to an uncertainty of less than $2 \%$. A schematic of the liquid supply system is shown in Fig. 4. More details about the wind tunnel as well as the injection system can be found in Lin et al. ${ }^{6,7}$ and references cited therein.

\section{$\underline{\text { Instrumentation }}$}

Single- and double-pulse shadowgraphy and holography were used to observe the properties of the aerated-liquid jets and the ligaments and drops produced by primary breakup. Two frequencydoubled Nd:YAG lasers with a wavelength of 532 $\mathrm{nm}$ and a pulse duration of $7 \mathrm{~ns}$ were used as the light source to expose the pictures. The pulse duration was short enough to essentially freeze the flow. Both an off-axis holocamera arrangement and regular photography (provided by blocking the reference beam) were used to observe the flow. Reconstruction of double-pulse holograms and shadowgraph pictures yielded two images of the flow so that liquid surface and drop velocities could be found given the known time of separation between the two pulses (as short as $100 \mathrm{~ns}$ ).

The hologram reconstruction system involved a helium-neon laser with the reconstructed image observed using a CCD camera. The optics yielded a magnified view of the image on the monitor equivalent to a $0.7 \times 0.8 \mathrm{~mm}$ region of the flow. The optical data was obtained using a frame grabber (Data Translation DT2851) and processed using Media Cybernetics Image-Pro Plus Software. Various locations of the hologram reconstruction were observed by transversing the hologram in two directions, and the video camera in the third direction using stepping motor-driven linear traversing systems (Velmex, Motel VP9000) having $1000 \mathrm{~nm}$ positioning accuracies. The combined holocamera/reconstruction system allowed objects as small as $2 \mu \mathrm{m}$ to be seen and the size of objects as small as $10 \mu \mathrm{m}$ to be measured with $10 \%$ accuracy. The reconstruction system was also used to measure flow properties from shadowgraph photographs with the photographs placed in the hologram holder and two-dimensional traversing as before.

Pictures of reference objects (needles) having known dimensions were used to correlate measurements on the monitor of ligament and drop sizes as well as drop velocities (from double-pulse exposures) to real dimensions. Drops generally were spherical and could be represented by an average diameter. Experimental uncertainties for drop diameters larger than $10 \mu \mathrm{m}$ were less than $10 \%$, increasing inversely to the drop diameter for smaller sized drops.

\section{$\underline{\text { Test Conditions }}$}

Test conditions are summarized in Table 1. The test conditions were varied by considering three different liquids, water, ethyl alcohol and glycerol, ejecting through round nozzle orifices having 0.5 and $1.0 \mathrm{~mm}$ diameter for liquid jet velocities of 17 $54 \mathrm{~m} / \mathrm{s}$ based on no aerating gas flow (GLR=0). Properties of each test liquid were measured before the experiments were conducted. Liquid densities were measured using a hydrometer having an accuracy of $0.5 \mathrm{~kg} / \mathrm{m}^{3}$. Cannon/Fenske viscometers were used to measure liquid viscosities with an uncertainty of less then $0.3 \%$. The liquid surface tension in air was measured using a ring tensiometer which has an accuracy of $5 \times 10^{-4} \mathrm{~N} / \mathrm{m}$.

The freestream total pressure was $\mathrm{P}_{\infty}=0.21$ Mpa and the total temperature varied between $\mathrm{T}_{0, \infty}=291-533 \mathrm{~K}$. The Mach number was constant and equal to $M=1.94$. Nitrogen was used as the barbotage gas. Liquid and barbotage gas injection pressures were in the range $\mathrm{P}_{\mathrm{inj}}=0.20-3.21 \mathrm{Mpa}$, and 
the gas/liquid mass flow rate ratio was varied in the range GLR $=0-10 \%$. The liquid/air momentum flux ratio, $q=\rho_{L} v_{L}{ }^{2} / \rho_{\infty} u_{\infty}{ }^{2}$, was found from the liquid flow rate and the diameter of the nozzle orifice under the assumption that no gas was present inside the nozzle, i.e. $G L R=0$, throughout the experiment. According to this definition, the momentum flux ratio was in the range $\mathrm{q}=1-15$ during the present investigation. It should be noted, however, that the actual momentum flux ratio for the aearated jet is larger due to the reduced effective nozzle area for the liquid, which is caused by the presence of the gas phase inside the nozzle. For a given liquid flow rate, the presence of the internal gas phase therefore has the effect of increasing liquid velocities.

\section{RESULTS AND DISCUSSION}

Spray Visualization

Typical shadowgraph images for water jets ejecting from a $1.0 \mathrm{~mm}$ nozzle orifice and aerated with various amounts of nitrogen are shown in Fig. 5. The supersonic crossflow is flowing from left to right at a Mach number of 1.94 and a total pressure of $0.21 \mathrm{MPa}$. The un-aerated momentum flux ratio between the liquid and the crossflowing air was held constant at $\mathrm{q}=3$ in all three pictures by keeping the liquid volumetric flow rate constant.

Picture (a) on the left of Fig. 5 shows a pure liquid jet ejecting into supersonic crossflow. The aerodynamic force of the freestream air, along with instabilities along the liquid column, breaks the column into ligaments and drops on the downwind side. The second picture (b) shows the same liquid jet but with $2 \%$ aerating nitrogen mass flow added to the liquid. Inside the nozzle orifice, the liquid now forms an annular sheet that is seen to expand to a conical shape immediately upon ejecting from the nozzle orifice. This expansion is caused by the internal gas phase which is choked and underexpanded at the nozzle exit. With increasing vertical distance from the nozzle exit, the outer dimension of the liquid cone expands to more than 3 times the initial jet diameter before aerodynamic forces of the crossflow turn the upstream side of the cone straight towards the vertical direction and later further downstream. It is important to note that unlike the pure-liquid jet, which shows ligament and drp formation only on the downstream side of the jet, the aerated-liquid jet displays primary breakup at the liquid surface even on its upstream side, suggesting considerable influence of the internal gaseous shear layer on the primary breakup machanism of the liquid sheet. As the aeration level is further increased to GLR $=6 \%$, as shown in picture (c) of Fig. 5, the cone angle near the nozzle is seen to increase. As a result, effects of the crossflow are further reduced and the area penetrated by the spray increases. The larger aeration level also enhances the primary breakup at the liquid surface both on the upstream and the downstream sides of the jet, as can be seen when comparing picture (b) and (c) of Fig. 5. Although the final penetration height is not visible on the pictures shown in Fig. 5, Lin et al. ${ }^{8}$ showed that penetration heights of the spray progressively increase with increasing aeration levels, i.e. from left to right in Fig. 5.

\section{Properties of the Liquid Sheet}

Figure 6 is a plot of the measured cone angles of the spray as a function of the ratio between the stagnation pressure of the injection system and the static pressure of the crossflowing freestream behind a normal shock. Both the angles between the vertical direction and the upstream side as well as the downstream side of the spray were measured near the exit of the nozzle orifice before aerodynamic forces significantly affect the trajectory of the spray. The upwind angle, $\Theta_{1}$, is found to be generally smaller than the downwind angle, $\Theta_{2}$, due to affects of the crossflow. This difference, however, is surprisingly small, indicating that the crossflow has only weak influence on the spray in the near injector region. The measurements are compared to the theoretical Prandtl-Meyer expansion angle that is driven by the remaining static pressure difference between the crossflowing ambient air and the underexpanded gas at the exit of the choked nozzle orifice. Measurements and predictions are in good agreement. The measured cone angles tend to be smaller than the predictions due to effects of the crossflow, effects of the surrounding annular liquid sheet on the internal gas phase, and pressure losses inside the injector assembly.

Double-pulse measurements of velocities at the surface of the liquid sheet are shown in Fig. 7 as a function of vertical distance from the nozzle exit. The measurements considered water and glycerol liquids and nozzle diameters of 0.5 and $1.0 \mathrm{~mm}$. Gas/liquid mass ratios were in the range GLR $=1$ $10 \%$. The velocities are normalized by the 
theoretical liquid velocity obtained from the dynamic pressure, $\left(2\left(\mathrm{P}_{\text {inj }}-\mathrm{p}_{\mathrm{G}, \mathrm{cr}}\right) / \rho_{\mathrm{L}}\right)^{1 / 2}$, which is based on the difference between the stagnation pressure of the liquid and the static pressure of the choked gas phase inside the nozzle orifice. The vertical distance from the nozzle, $\mathrm{y}$, is normalized by the nozzle diameter, $\mathrm{d}_{\text {inj. }}$. The velocity coefficient, which is the average ratio between measured and theoretical velocities, is found to equal $\mathrm{C}_{\mathrm{v}}=0.84$, confirming expected losses due to wall effects and pressure losses. Despite large relative velocities between the liquid phase and the internal gas phase, the vertical distance from the nozzle does not appear to have a significant effect on liquid velocities. This also shows that boundary layer effects from the wall of the nozzle orifice do not influence the present velocity measurements at the vertical distances considered. The scatter of the measurements is due to difficulties of accurately measuring velocities right at the liquid surface.

Knowing the velocity of the liquid phase allows the initial thickness of the annular liquid sheet to be estimated based on the liquid volumetric flow rate as follows:

$$
\begin{gathered}
\mathrm{A}_{\mathrm{L}}=\dot{\mathrm{Q}}_{\mathrm{L}} / \mathrm{v}_{\mathrm{L}} \\
\Leftrightarrow \mathrm{b}_{\text {inj }} / \mathrm{d}_{\mathrm{inj}}=1 / 2\left\{1-\left[1-4 \dot{\mathrm{Q}}_{\mathrm{L}} /\left(\mathrm{v}_{\mathrm{L}} \mathrm{d}_{0}^{2}\right)\right]^{1 / 2}\right\}
\end{gathered}
$$

Figure 8 is a plot of Eq. (2) for a range of flow coefficients $\mathrm{C}_{\mathrm{v}}=0.8-1.0$. As expected, the liquid sheet thickness is seen to progressively increase with increasing liquid volumetric flow or decreasing liquid velocity, respectively. It approaches the pureliquid state, $\mathrm{b}_{\mathrm{inj}} / \mathrm{d}_{\mathrm{inj}}=0.5$, at a particular flow condition that depends on the flow coefficient, $\mathrm{C}_{\mathrm{v}}$. Since direct observation of the flow inside the nozzle was not possible, the initial liquid sheet thickness was estimated based on the liquid volumetric flow rate (Fig. 8) and the measured liquid velocities (Fig. 7). It should be noted that the initial liquid sheet thickness rapidly decreases with increasing vertical distance from the nozzle exit due to the conical nature of the spray, i.e. to roughly $30 \%$ of the initial thickness when the outer dimension of the cone reaches three times the initial nozzle diameter.

Analogous to the breakup of round pureliquid jets, aerated-liquid jets disintegrate into droplike segments at the end of the liquid core. These drops subsequently are subject to secondary drop breakup. Locations of the completion of the primary breakup process in the direction of the liquid jet flow were measured from the present experiments and normalized by the characteristic liquid breakup time due to Ranger and Nicholls ${ }^{13}, t^{*}=d_{L} / u_{\infty}\left(\rho_{L} / \rho_{G}\right)^{1 / 2}$. For the present measurements, the dimension of the liquid phase was taken to be the hydraulic diameter of the initial liquid sheet, $d_{L}=2 b_{i n j}$, whereas velocity and density of the gas phase corresponded to the condition of the crossflowing freestream behind a normal shock wave. Measurements of normalized breakup times as a function of gas/liquid mass ratio are plotted in Fig. 9 for water and alcohol sprays for nozzle diameters of 0.5 and $1.0 \mathrm{~mm}$. For pure-liquid jets $(\mathrm{GLR}=0 \%)$, the present results for breakup times of liquid columns in supersonic crossflows are in excellent agreement with the measurements of Sallam et al. $^{14}$ for the breakup times of round nonturbulent liquid jets in subsonic crossflows, i.e. $t_{b} / t^{*}=2.5$. When the round liquid jets are aerated by injecting gas into the liquid flow prior to the nozzle exit orifice, however, breakup times of the liquid core undergo a transition to $\mathrm{t}_{\mathrm{b}} / \mathrm{t}^{*}=5.1$ at GLR at or above $2 \%$. These results suggest that the effect of the crossflow on the primary breakup of aerated liquid jets in the annular flow regime is somewhat reduced as compared to the primary breakup of round pureliquid jets. Full understanding of the breakup of aerated liquid jets, however, requires further study of the effect of the internal gas phase on the surrounding liquid sheet.

\section{Structure of the Dense Spray}

Outcomes of primary breakup of aerated liquid jets in supersonic crossflows are considered next. The formation of ligaments followed by the creation of droplets at the end of the ligaments is inherent to the present breakup mechanism (see Fig. 5 ). Measurements of ligament diameters, that were observed at the surface of the liquid sheet, are plotted in Fig. 10 as a function of GLR. Results are shown for water, alcohol and glycerol sprays for nozzle diameters of 0.5 and $1.0 \mathrm{~mm}$. The large range of test parameters, however, does not appear to have a significant effect on ligament diameters, which have an average size of $\mathrm{d}_{\text {lig }}=29 \mu \mathrm{m}$. Thus, unlike the primary shear breakup of round pure-liquid jets in subsonic crossflows, where ligament diameters are at least a function of the jet diameter in the quasisteady regime (see Sallam et al. ${ }^{14}$ ), no discernible effect of nozzle diameter, GLR or liquid properties on ligament sizes of aerated-liquid jets in crossflows could be observed during the present investigation. 
Figure 10 also includes a plot of the Sauter mean diameters, SMD, of drops that are found in the dense spray region that extends right up to the liquid jet itself. Each data point represents the SMD of a large range of drops along the liquid surface at a particular spray condition. Similar to the ligament diameters, no significant effect of nozzle diameter, GLR or liquid properties on the average drop sizes can be observed. The average SMD of the present investigation is $\mathrm{SMD}_{0}=43 \mu \mathrm{m}$. The drop/ligament diameter ratio is therefore near 1.9 , which is typical of Rayleigh breakup, see Sallam et al. ${ }^{14}$

The same measurements for ligament diameters and drop SMDs that are reported in Fig. 10 are also plotted in Fig. 11, but this time plotted as a function of the liquid/gas momentum flux ratio, q. The results indicate that also the momentum flux ratio has no discernible effect on ligament and drop sizes for the present range of aerated liquid jets in supersonic crossflows. Averages as a function of the momentum flux ratio are found to be $\mathrm{d}_{\mathrm{lig}}=29 \mu \mathrm{m}$ for the ligament diameters and $\mathrm{SMD}_{0}=41 \mu \mathrm{m}$ for the average drop sizes. These results agree with observations made by Kim and Lee ${ }^{12}$ who also found that drop SMDs asymptotically approach a constant value of $40 \mu \mathrm{m}$ as soon as the annular flow regime is reached by increasing GLR. The fact that drop sizes are not affected by any of the parameters considered in the present study, however, is remarkable and clearly merits further investigation.

Drop size distributions are illustrated in Fig. 11. Drop sizes were measured across a broad vertical distance along the spray surface for water, alcohol and glycerol jets produced using 0.5 and 1.0 $\mathrm{mm}$ nozzles. Aeration levels were in the range GLR $=1-8 \%$. The mass median diameter, MMD, of each group was used to normalize drop sizes, which were plotted according to a root/normal scale representing the cumulative liquid volume. From the remarkably straight lines exhibited by the measurements it is evident that the drops generated at the liquid surface satisfy Simmons ${ }^{15}$ universal root-normal drop-size distribution function for all spray conditions presently considered. The average ratio between mass median diameter and Sauter mean diameter of the measurements equals $\mathrm{MMD} / \mathrm{SMD}=1.07$, which is significantly smaller than the ratio of 1.2 observed by Simmons ${ }^{15}$ and Ruff et al. ${ }^{16}$ and indicates more uniform drop sizes for aerated injection. This behavior is not surprising, however, in view of the relatively weak affect of other properties of the present sprays on drop sizes.

\section{CONCLUSIONS}

The primary breakup of aerated (effervescent) liquid jets in supersonic crossflow was investigated experimentally, using single- and double-pulse shadowgraphy and holography. Test conditions involved pure-liquid and aerated-liquid water, alcohol and glycerol jets ejecting through round nozzle orifices having 0.5 and $1.0 \mathrm{~mm}$ diameters at aeration levels of GLR $=0-10 \%$ and liquid/gas momentum flux ratios of $q=1-11$. The major conclusions of the study are as follows:

1. Cone angles and surface breakup properties along both the upstream and downstream sides of the jet suggest weak aerodynamic effects due to the crossflow near the jet exit.

2. The average discharge velocity of the liquid sheet is related to the difference between the liquid stagnation pressure and the static pressure of the choked gas flow inside the nozzle orifice.

3. Breakup times of aerated liquid jets (the liquid sheet) can be correlated with a constant normalized breakup time, analogous to but somewhat larger than the primary breakup of a pure-liquid jet in a subsonic crossflow.

4. Ligament and drop sizes after primary breakup are relatively constant and independent of the final discharge orifice diameter, aeration level (GLR), liquid/gas momentum flux and the liquid properties considered during the present investigation. The average drop diameter was 40 $\mu \mathrm{m}$.

5. Drop size distributions in the dense spray region region near the liquid surface satisfied Simmons' root-normal distribution function, with $\mathrm{MMD} / \mathrm{SMD}=1.07$.

\section{ACKNOWLEDGMENTS}

This research was supported by Taitech, Inc. under a subcontract from Taitech's base contract F33615-03-D-2326 with the U.S. Air Force. Assistance from the air facility group of the Air 
Force Research Laboratory and assistance from R. Jolly, D. Ma, S. Wang and M. Zuzolo under the University of Michigan Undergraduate Research Opportunity Program is gratefully acknowledged.

\section{REFERENCES}

[1] Lefebvre, A. H., Wang, X. F., and Martin, C. A., "Spray Characteristics of Aerated-Liquid Pressure Atomizers," Journal of Propulsion and Power, Vol 4, No. 4, 1988, pp. 293 -298.

[2] Fuller, R. P., Wu, P.-K., Kirkendall, K. A., and Nejad, A. S., "Effects of Injection Angle on Column Breakup Processes of Liquid Fuel Jets in Subsonic Crossflows," AIAA Paper No. 97-2966, 1997.

[3] Wu, P.-K., Kirkendall, K. A., Fuller, R. P., and Nejad, A. S., "Breakup Processes of Liquid Jets in Subsonic Crossflows," AIAA Journal, Vol. 13, No.1, 1997, p. 64.

[4] Mazallon, J., Dai, Z., and Faeth, G. M., "Primary Breakup of Nonturbulent Round Liquid Jets in Gas Crossflows," Atomization and Sprays, Vol. 9, No. 3, 1999, pp. 291-311.

[5] Sallam, K. A., Dai, Z., and Faeth G. M., "Drop Formation at the Surface of Plane Turbulent Liquid Jets in Still Gases," International Journal of Multiphase Flow, Vol. 25, No. 6-7, 1999, pp. 1161-1180.

[6] Lin, K.-C., Kennedy, P. J., and Jackson, T. A., "Spray Structures of Aerated-liquid Fuel Jets in Supersonic Crossflows," AIAA Paper No. 99-2374, 1999.

[7] Lin, K.-C., Kennedy, P. J., and Jackson, T. A., "Spray Penetration Heights of Angleinjected Aerated-liquid Jets in Supersonic Crossflows," AIAA Paper No. 2000-0194, 2000.

[8] Lin, K.-C., Kennedy, P. J., and Jackson, T. A., "Spray Structure in Aerated-liquid Jets in
Subsonic Crossflows," AIAA Paper No. 20010300, 2001

[9] Lin, K.-C., Kennedy, P. J., and Jackson, T. A., "Penetration Heights of Liquid Jets in High-speed Crossflows," AIAA Paper No. 2002-0873, 2002.

[10] Lin, K.-C., Kennedy, P. J., and Jackson, T. A., "Structures of Aerated-liquid Jets in HighSpeed Crossflows," AIAA Paper No. 20023178, 2002.

[11] Mathur, T., Lin, K.-C., Kennedy, P. J., Gruber, M., Donbar, J., and Jackson, T. A., "Liquid JP-7 Combustion in a Scramjet Combustor," AIAA Paper No. 2000-3581, 2000.

[12] Kim, J. Y. and Lee, S. Y., "Dependence of Spraying Performance on the Internal Flow Pattern in Effervescent Atomizers," Atomization and Sprays, Vol. 11, 2001, pp. 735-756.

[13] Ranger, A.A., and Nicholls, J.A., "The Aerodynamic Shattering of Liquid Drops," AIAA Journal, Vol. 7, No. 2, 1969, pp. 285290.

[14] Sallam, K. A., Aalburg, C., and Faeth, G. M., "Breakup of Round Nonturbulent Liquid Jets in Gaseous Crossflows," AIAA Paper No. 2003-1326, 2003.

[15] Simmons, H. C., "The Correlation of DropSize Distributions in Fuel Nozzle Sprays," Journal of Engineering for Power, Vol. 99, 1977, pp. 309-319.

[16] Ruff, G. A., Wu, P.-K., Bernal, L. P., and Faeth, G. M., "Continuous- and DispersedPhase Structure of Dense Nonevaporating Pressure-Atomized Sprays," Journal of Propulsion and Power, Vol. 8, No. 2, 1992, pp. 280-289. 
Table 1. Summary of the test conditions. ${ }^{\mathrm{a}}$

Liquid

Density, $\mathrm{kg} / \mathrm{m}^{3}$

Liquid/gas density ratio, $\rho_{\mathrm{L}} / \rho_{\mathrm{G}}$

Viscosity, $\mathrm{kg} / \mathrm{ms} \times 10^{4}$

Liquid/gas viscosity ratio, $\mu_{\mathrm{L}} / \mu_{\mathrm{G}}$

Surface tension, $\mathrm{N} / \mathrm{m} \times 10^{-3}$

Jet exit diameter, mm

Gas/liquid mass ratio, GLR

Liquid/gas momentum ratio, $\mathrm{q}$
Water

997

640-1170

8.94

0.48

70.8

$0.5,1.0$

$0-10$

$1-16$
Ethyl Alcohol

Glycerol $(79 \%)^{\mathrm{b}}$

1205

772-1413

37.3

2.02

59.8

24.0

$0.5,1.0$

$0.5,1.0$

$0-8$

$0-8$

$1-15$

${ }^{a}$ Air crossflow at Mach number $\mathrm{M}=1.94$ with stagnation pressure $\mathrm{P}_{\infty}=0.21 \mathrm{MPa}$ and stagnation temperatures $\mathrm{T}_{0, \infty}=291-533 \mathrm{~K}$. Static properties behind a normal shock were $\mathrm{u}_{\infty}=195-263 \mathrm{~m} / \mathrm{s}, \mathrm{p}_{\infty}=0.12 \mathrm{MPa}$ and $\mathrm{T}_{\infty}=272-498 \mathrm{~K}$. ${ }^{\mathrm{b}}$ Percentage glycerin by mass in parenthesis.

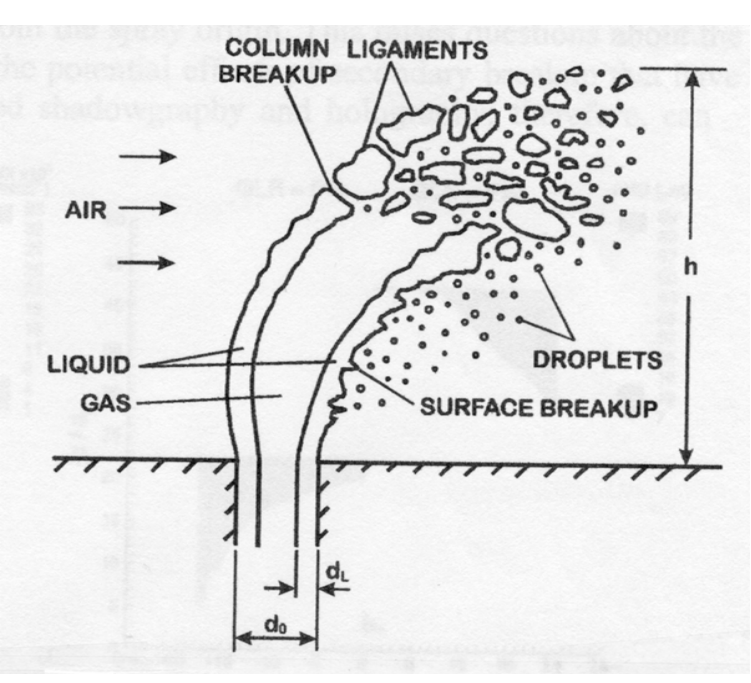

Fig. 1 Sketch of typical aerated-liquid jet ejecting into a crossflow.

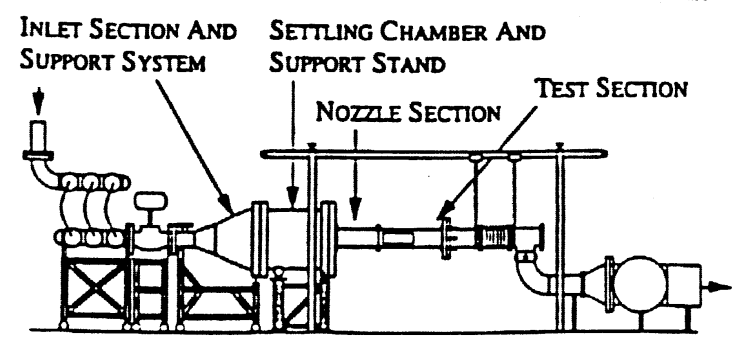

Fig. 2 Schematic of the wind tunnel.

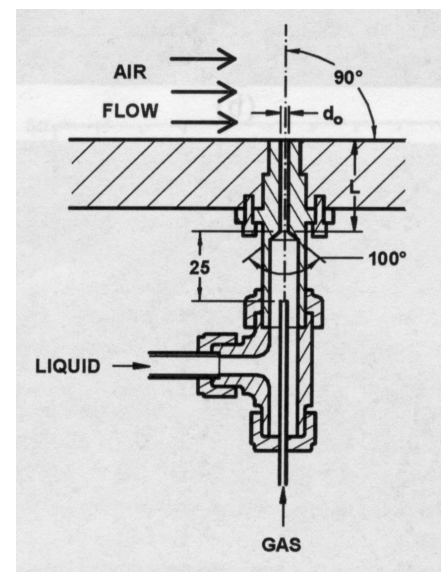

Fig. 3 Schematic of the injector assembly.

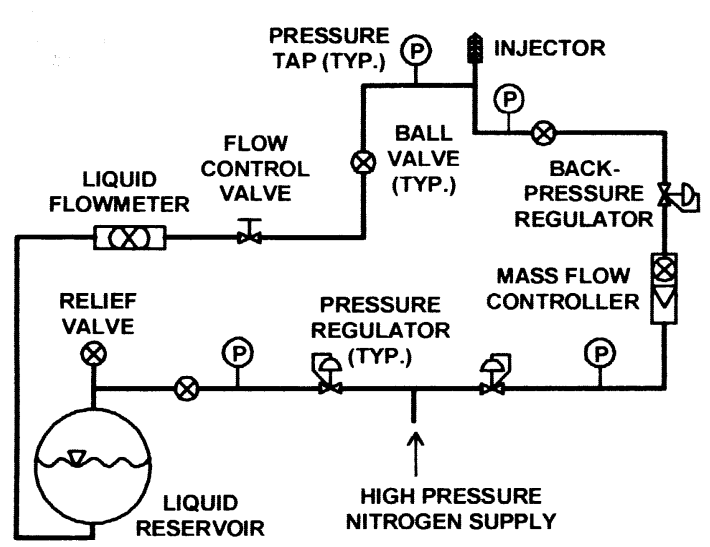

Fig. 4 Schematic of the liquid supply system 


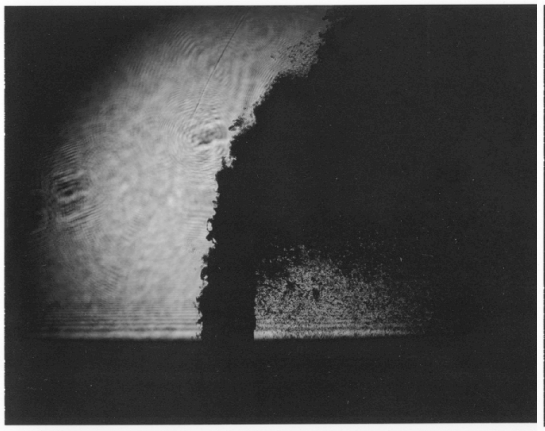

(a) $\mathrm{GLR}=0 \%$

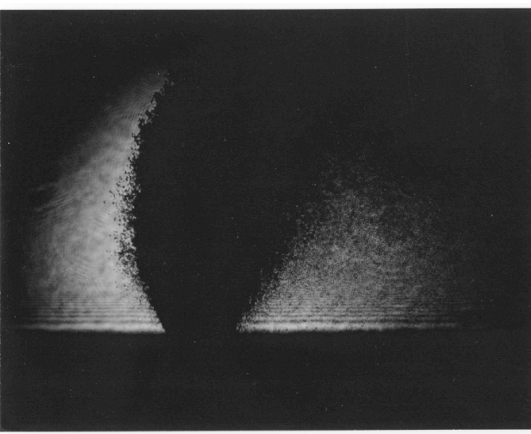

(b) $\mathrm{GLR}=2 \%$



(c) $\mathrm{GLR}=6 \%$

Fig. 5 Shadowgraph images of water jets at various aeration levels $\left(\mathrm{d}_{0}=1.0 \mathrm{~mm}, \mathrm{M}=1.94, \mathrm{q}=3\right)$.



Fig. 6 Spread angles of aerated-liquid jets in the near injector region as a function of injection pressure ratio.

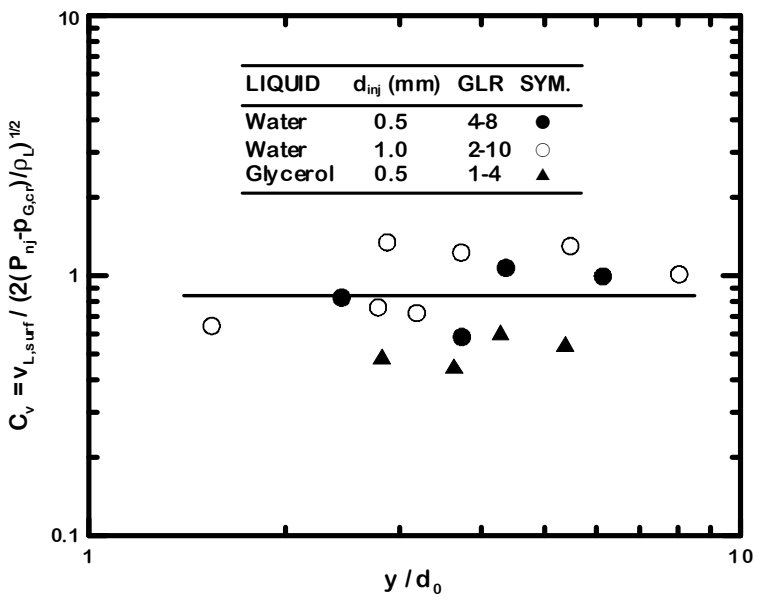

Fig. 7 Surface velocities of the liquid sheet in terms of a velocity coefficient as a function of vertical distance from the nozzle exit, for various liquids and nozzle diameters.

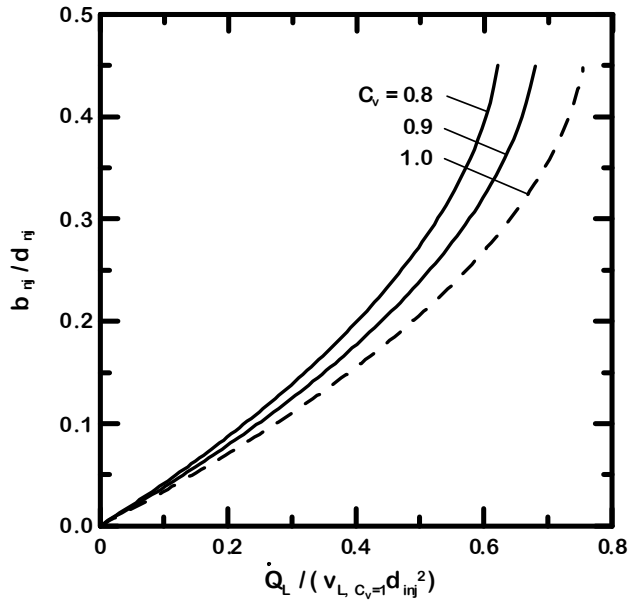

Fig. 8 Effects of the velocity coefficient on the relation between initial liquid sheet thickness, volumetric flow rate and injector diameter.

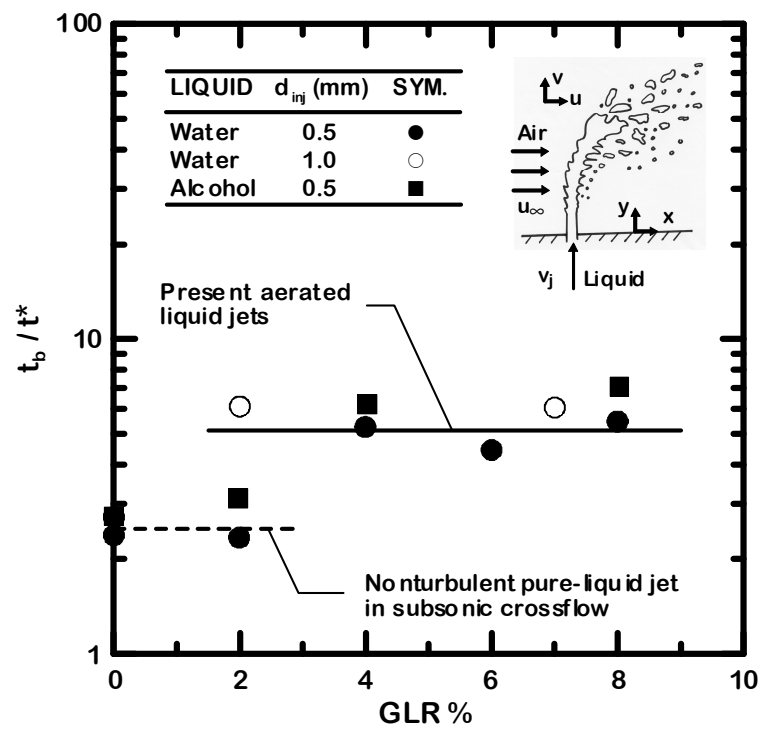

Fig. 9 Normalized breakup times of the liquid core of pure-liquid and aerated-liquid jets in supersonic crossflow as a function of gas/liquid mass ratio, for various liquids and nozzle diameters. 




Fig. 10 Diameters of ligaments and drops as a function of gas/liquid mass ratio, for various liquids and nozzle diameters.



Fig. 11 Diameters of ligaments and drops as a function of liquid/gas momentum flux ratio, for various liquids and nozzle diameters.

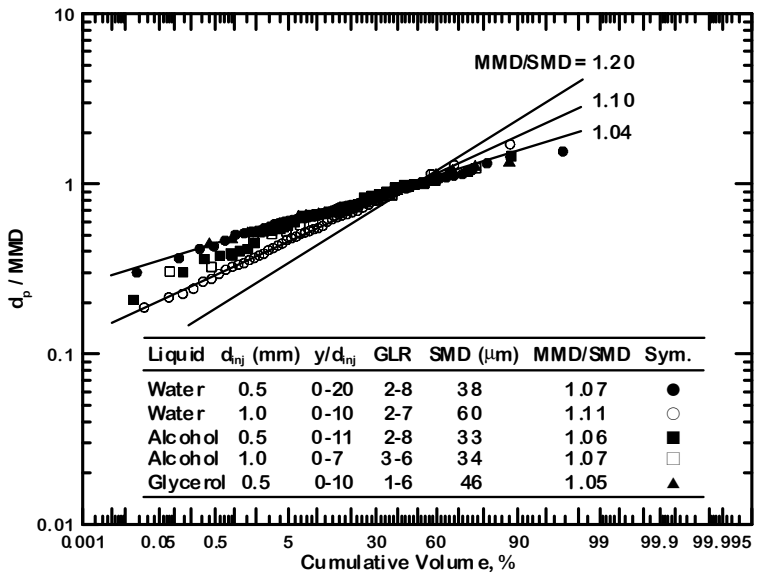

Fig. 12 Drop size distributions at the liquid surface for various liquids and nozzle diameters. 